\title{
ENERGY EFFICIENT DESIGN OF EHF-5G ANTENNAS WITH ENHANCED BANDWIDTH FOR NAVIGATION SATELLITE APPLICATIONS
}

Elayaraja Chinnathambi

Research Scholar/AP/Department of Electronics and Communication, Dhaanish Ahmed College of Engineering, Anna University, Chennai, Tamil Nadu, (India).

E-mail: celaiyaraja@gmail.com ORCID: https://orcid.org/0000-0001-8063-0472

\begin{abstract}
Amali Chinnappan
Assistant Professor, Department of Electronics and Communication, SRM Valliammai Engineering College (Autonomous), Anna University, Chennai, (India).

E-mail: amalic.ece@valliammai.co.in ORCID: https://orcid.org/0000-0001-6246-1433
\end{abstract}

Kannan Sivabaskaran Student, Department of Electronics and Communication (ECE), Dhaanish Ahmed College of Engineering, Chennai, (India).

E-mail: kannankasi12@gmail.com ORCID: https://orcid.org/0000-0003-1739-3026

Sridhar Bilvam

Professor, Department of ECE, Mohamed Sathak A. J. College of Engineering, Anna University, Chennai, (India). E-mail: mbsridhar_1969@yahoo.co.in ORCID: https://orcid.org/0000-0003-3417-911X

Recepción: 28/11/2019 Aceptación: 11/12/2020 Publicación: 30/11/2021

\section{Citación sugerida:}

Chinnathambi, E., Chinnappan, A., Sivabaskaran, K., y Bilvam, S. (2021). Energy efficient design of EHF-5G antennas with enhanced bandwidth for navigation satellite applications. 3C Tecnología. Glosas de innovación aplicadas a la pyme, Edición Especial, (noviembre, 2021), 537-551. https://doi. org/10.17993/3ctecno.2021.specialissue8.537-551 


\section{ABSTRACT}

The 5th Generation of wireless communication aims at increasing data transfer rate and system capacity while reducing latency, energy consumption to make it affordable. In accordance with International Telecommunication Union (ITU), $3.4 \mathrm{GHz}$ to $3.6 \mathrm{GHz}$ range in Sub-6 GHz unlicensed Band was used earlier to provide comparatively higher Bandwidth than 4G LTE networks. Even though the complexity in the development of infrastructure is lesser in Sub-6 GHz band, in order to achieve Improved Performance, 5G Networks are implemented in the 24 to $86 \mathrm{GHz}$ bands of Extremely High Frequency (EHF) range of 30 to $300 \mathrm{GHz}$. This Paper proposes 2 Different Antenna Structures which can Transceiver Signals with Frequencies in the EHF Spectrum (mm-Wave $(\mathrm{mmW})$ ) for Earth Exploration Satellite and Radio Navigation Satellite Applications. According to ITU, $24.5 \mathrm{GHz}$ to the $29.5 \mathrm{GHz}$ band is allocated for $5 \mathrm{G}$ Network Implementations in India. Instead of the usage of complex techniques like Wide Bandwidths and Massive MIMO, Antenna Miniaturization could be used to achieve 5G performance.

\section{KEYWORDS}

5G, ITU, EHF, mm Wave (mmW), Massive MIMO, Antenna Miniaturization. 


\section{INTRODUCTION}

Mobile cellular networks are expected to support ever-growing data rate demands of the consumer meanwhile tackling the increased resultant traffic. Antenna design has become an integral part of any handset owing to the demand for wireless communication.

The end users, manufacturers and service providers demand wireless units with antennas that are small and compact, cost effective for manufacturability, low profile and easy to integrate with the wireless communication system. In this paper, mm-wave wireless systems requirements were fulfilled by the proposed antenna structures.

ITU-R Radio Regulations defines the Earth Exploration Satellite Service (EESS) as a radio communication service with a goal of monitoring the conditions of the earth and the atmosphere. This involves observation of the earth's environment for factors like sea ice monitoring, stratospheric ozone depletion, tropospheric pollution, surface monitoring, middle atmosphere chemistry, and glaciology. The information thus collected is used for weather forecasts and to warn the areas with higher probability of getting affected by storms, heavy rain and cyclones.

A Radio Navigation Satellite Service (RNSS) is a Radio determination service using satellites for radio navigation, and is also referred to as a safety-of-life service. Feeder links may also be included to ensure effective operation. RNSS must be protected from interferences to achieve accuracy. Both passive and active sensing are included to control the satellites using tele command and also to send information to earth from the satellites using telemetry thereby collecting information by using a wide variety of set frequencies.

Environmental issues are addressed by interpretation of these long-term collected data. The band of frequencies between $30 \mathrm{GHz}$ and $300 \mathrm{GHz}$ in the electromagnetic spectrum is designated by ITU as Extremely High Frequencies (EHF), which lies between the Super High Frequency band and Far-Infrared band whose lower part is known as Tetra-hertz Gap.

Radio waves in this band are characterized by wavelengths from ten to one millimeter, which makes this band the millimeter band and radiation in this band millimeter waves (MMW or mmW). Millimeter waves are not reflected by the ionosphere as they propagate 
only by Line Of Sight (LOS) paths unlike lower frequency radio waves which travel as ground waves along the earth surface. These millimeter waves are blocked by building walls to get attenuated. The $5 \mathrm{G}$ technology is driven by eight specification requirements as follows

- 10 to $100 x$ improvement in data rate.

- $\quad$ Latency or delay of 1 millisecond.

- $1000 \mathrm{x}$ bandwidth available per unit area covered.

- 100x improvement in number of connected devices.

- $99.999 \%$ availability of network.

- $\quad 100 \%$ network coverage.

- $\quad 90 \%$ reduction in energy consumption.

- Improved battery life.

Further, the paper is detailed as follows: the works related to the same concept are presented in Section 2. The design of a Vivaldi Slot Antenna to operate at a frequency of $46.44 \mathrm{GHz}$ to be used for Radio Navigation Satellite applications is described in Section 3. In Section 4, the design of microstrip patch antenna to operate at a frequency of $58.837 \mathrm{GHz}$ to be used for earth exploration Satellite Applications is explained. Section 5 interprets the simulation results observed on designing both the Antenna structures. Section 6 concludes the paper.

\section{MATERIALS AND METHODS}

\subsection{RELATED WORKS}

The design principles and equations in accordance to which the Antennas proposed in this paper are designed to operate at specified resonant frequencies were presented (https:// nptel.ac.in/) (Balanis, 2005; Kraus, 1951). The applications and services of antennas designed to resonate at various frequencies in the range of $3 \mathrm{GHz}$ to $300 \mathrm{GHz}$ are listed (https://cdn.rohdeschwarz.com/). Impact of modifying ground plane of an antenna on its resonant frequency, Bandwidth and Gain are observed (Picher et al., 2013). Ability of a Vivaldi structure to resonate at millimeter wave frequencies like $77 \mathrm{GHz}$ and $53 \mathrm{GHz}$ when 
fed by a unilateral fin line and then transmitted to its taper slotline radiator is explained (Chong, Ng, \& Fu, 2003; Priyadarshi et al., 2017).

Principles involved in design of printed microstrip antennas for millimeter wave frequencies and the challenges in usage of EHF is explained (Bhartia, Tomar, \& Rao, 1991; Rappaport, Murdock, \& Gutierrez, 2011). A multislotted microstrip patch antenna is designed for WIFI and WLAN applications using probe feeding and multi-slotted patch to improve performance (Li \& Li, 2010). The design of two different microstrip patch antennas with different feeding mechanisms is explained and the results are compared and interpreted (Pozar \& Schaubert, 1995). The usage of Miniaturized Microstrip Antennas for future 5G applications is illustrated (Verma et al., 2016). Computer simulation technology-3D Electromagnetic simulation software (CST) tool is used to design the Vivaldi and micro strip patch antennas.

\subsection{VIVALDI SLOT ANTENNA}

A Vivaldi Slot Antenna is a simple Planar Antenna characterized by wide Bandwidth and Linearly Polarized output. One side of feed provided to the Vivaldi structure has a short circuit to act as a parallel inductor to ensure operation of these Antennas in Radio Frequency range. A radiating element is present on another side of the feed has which has a structure similar to a tapered slot antenna or an aperture antenna. An open space is excited by the feeding mechanism through a coaxial cable or a micro strip line and can be terminated with a direct coaxial connection or a sector-shaped area. This energy reaches an exponentially tapered pattern from the open space area through a symmetrical slot line.

The Proposed Antenna Structure has a size of $3.6 \mathrm{~mm} * 2.5 \mathrm{~mm} * 0.2 \mathrm{~mm}$ which occupies a minimal volume of space as in Figure 1. The Small slot within the structure gets excited by a Microstrip line feed as in 2 and continuous standing waves are produced within the structure which acts like a waveguide and channels the wave towards the opposite direction to the feed where an exponentially tapering aperture is placed which results in conversion to spherical waves which gets radiated into space. 


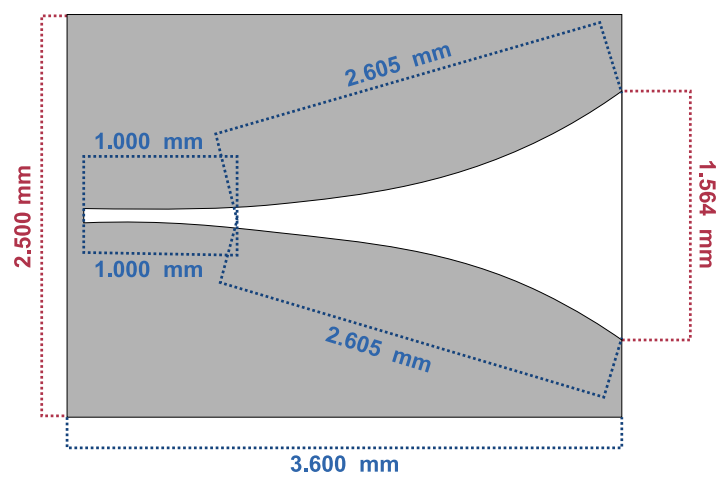

Figure 1. Front View of the Vivaldi Antenna.

Source: own elaboration.

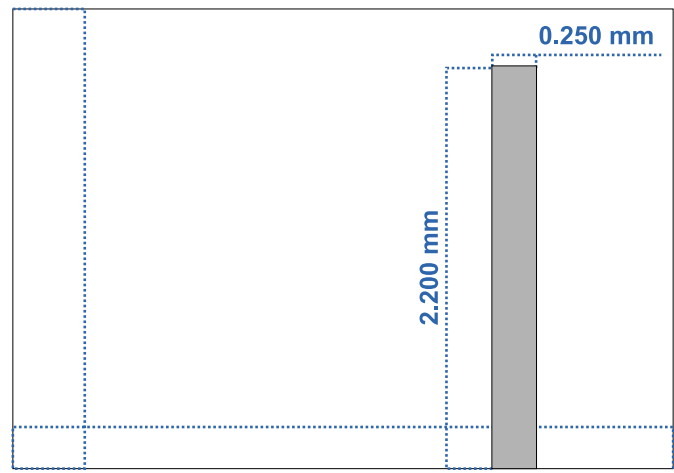

Figure 2. Rear View of the Antenna (Microstrip Feed).

Source: own elaboration.

The dielectric substrate used is Taconic RF-60A (lossy) with a dielectric permittivity of 6.15 and loss tangent of 0.0028. A Perfectly Electrically Conducting (PEC) material is used for feed and the top of the substrate.

\subsection{MICROSTRIP PATCH ANTENNA WITH INSET FEED}

Microstrip patch antennas can be printed directly onto a Printed Circuit Board, which makes the fabrication of this structure simple. Microstrip antennas are preferred in mobile phones because of its low cost, low profile and conformability. Further, the width of the patch is computed by using the Eq. (1).

The proposed antenna occupies a volume of $5 \mathrm{~mm} * 4 \mathrm{~mm} * 1.56 \mathrm{~mm}$ and makes use of FR-4 material as the dielectric substrate and copper (annealed) as the conducting patch are shown in Figure 3 and Figure 4. 


$$
W=\frac{c}{2 f_{0}\left(\sqrt{\frac{\varepsilon_{r}+1}{2}}\right)}
$$

Where,

W - Width of the patch

c - Velocity of light $\left(3 \times 10^{8} \mathrm{~m} / \mathrm{s}\right)$

$f_{0}$ - resonance frequency

عr - relative permittivity of the dielectric substrate FR4.

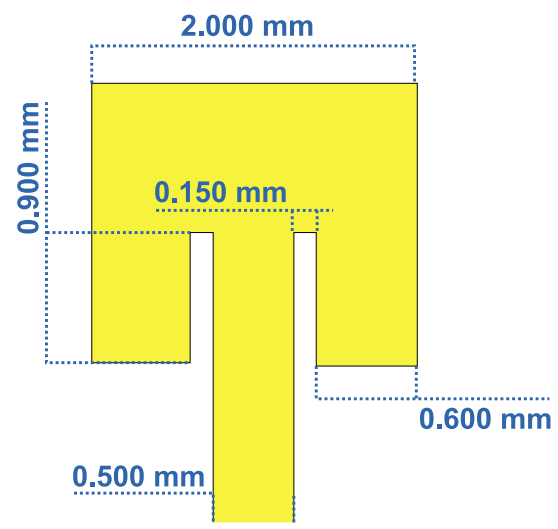

Figure 3. Front view of microstrip patch antenna with inset Feed.

Source: own elaboration.

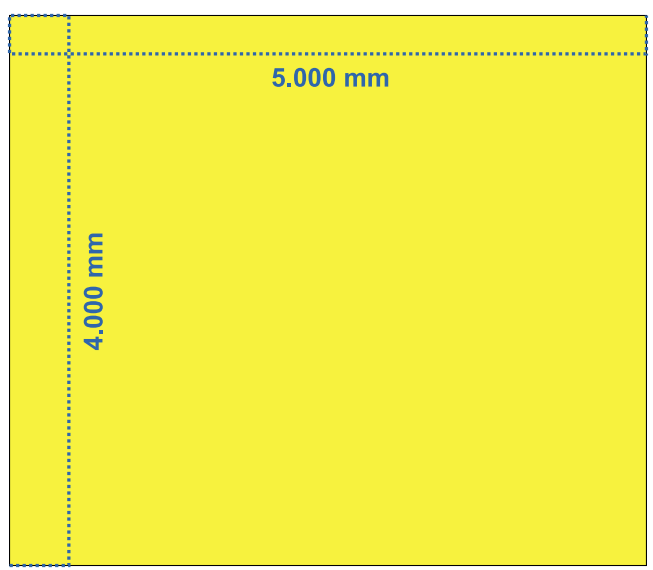

Figure 4. Ground plane of the microstrip patch antenna.

Source: own elaboration. 


\subsubsection{MATERIAL PROPERTIES}

\section{COPPER (ANNEALED):}

Electric Conductivity $=5.8 \mathrm{e}+07 \mathrm{~S} / \mathrm{m}$

Relative Permeability $=1.0$

Thermal Conductivity $=401.0 \mathrm{~W} / \mathrm{K} / \mathrm{m}$

Heat Capacity $=0.39 \mathrm{~kJ} / \mathrm{K} / \mathrm{kg}$

Material Density $=8930.0 \mathrm{~kg} / \mathrm{m}^{3}$

FR-4 (Lossy)

Relative Dielectric Permittivity $(\varepsilon r)=4.3$

Loss Tangent $(\tan \delta)=0.025$

Relative Permeability $=1.0$

Thermal Conductivity $=0.3 \mathrm{~W} / \mathrm{K} / \mathrm{m}$

\subsubsection{CHOICE OF DIELECTRIC SUBSTRATE MATERIAL (HTTPS://NPTEL.AC.IN/)}

Only in very few applications, an Alumina is used as a substrate for Microstrip Patch Antenna and most of the time that application could be a compact antenna. Typical dielectric constant ( $\varepsilon r$ ) of Alumina is 9.8 as in Table 1 even though it may vary from 9.6 to about 10.2 .

It has a very low loss tangent of 0.001 . Having a low loss tangent, dielectric losses would be very less. The only issue is its high cost; Alumina is not very useful as a substrate for an antenna because it is a high leads to very less radiation.

Table 1. Characteristics of different substrates.

\begin{tabular}{|c|c|c|c|}
\hline Substrate & Dielectric constant $(\boldsymbol{\varepsilon r})$ & Loss Tangent (tan $\mathbf{\delta})$ & Cost \\
\hline Alumina & 9.8 & 0.001 & Very High \\
\hline Glass Epoxy (FR-4) & 4.4 & 0.02 & Low \\
\hline Duroid / Arlon & 2.2 & 0.0009 & Very High \\
\hline Foam & 1.05 & 0.0001 & Low/ Medium \\
\hline
\end{tabular}

Source: own elaboration.

Teflon has a dielectric constant of 2.1 and the tan delta is very small it is 0.0009 or it has variation again 0.01 to about 0.0015 also, but again the cost is very high. Typically, fiber 
reinforced glass is used. In fact, epoxy is glassy material and it is obvious that glass cannot be used as it can be easily broken. So, these fiber glasses are used whose typical dielectric constant may vary from 2.1 to about 2.5.

Low cost alternative is to use glass epoxy substrate also popularly known as FR4 substrate. Now this is the commonly used substrate for all printed circuit boards. The typical dielectric constant can be 4.4 , but in reality, it may be from 3.8 to about 4.6. The problem with this is that the loss tangent is very high which is 0.02 , but the big advantage is that the cost of the Substrate is very low refractive index $=\sqrt{ } \varepsilon$ r, So, for FR-4 which is a glass epoxy substrate, refracting index of glass is 1.5 , its $\varepsilon$ r will be 1.5 squared which is 2.25 . FR-flame retardant (or) fire resistant. FR1 has higher Tg of $130^{\circ} \mathrm{C}$ than FR2 [150C]. Glass transition temperature $(\mathrm{Tg})$ is the temperature at which a material becomes mechanically unstable [gradual and reversible transition from brittle, hard, glassy state to rubbery or viscous state].

FR2- phenolic resin binder

FR3 - epoxy resin binder

FR4 - glass fiber epoxy laminate [most commonly used PCB material is FR4]

Usage Preference in china FR4 > FR1 > FR2.

FR1 and FR2 are used for 1 layer PGBs because they not good for passing holes. FR3 is not recommended or multilayer PCBs. FR4 is the best selection. Even though use of FR-4 material as the dielectric substrate reduces performance, this material is preferred as it is cost efficient.

\section{RESULTS}

\subsection{VIVALDI SLOT ANTENNA}




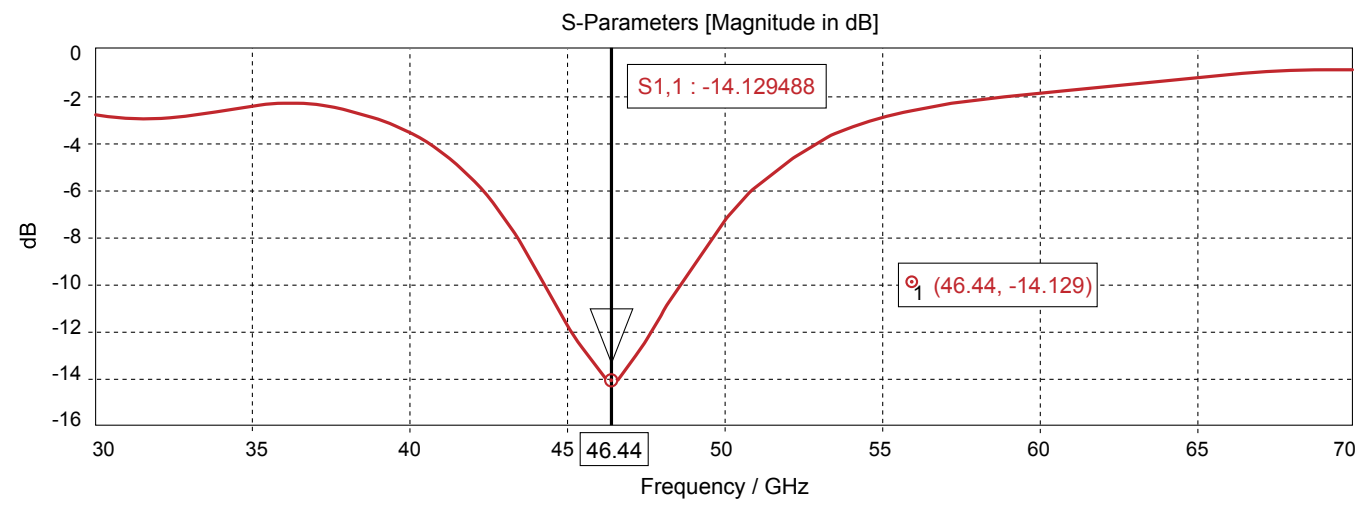

Figure 5. S11 plot.

Source: own elaboration.

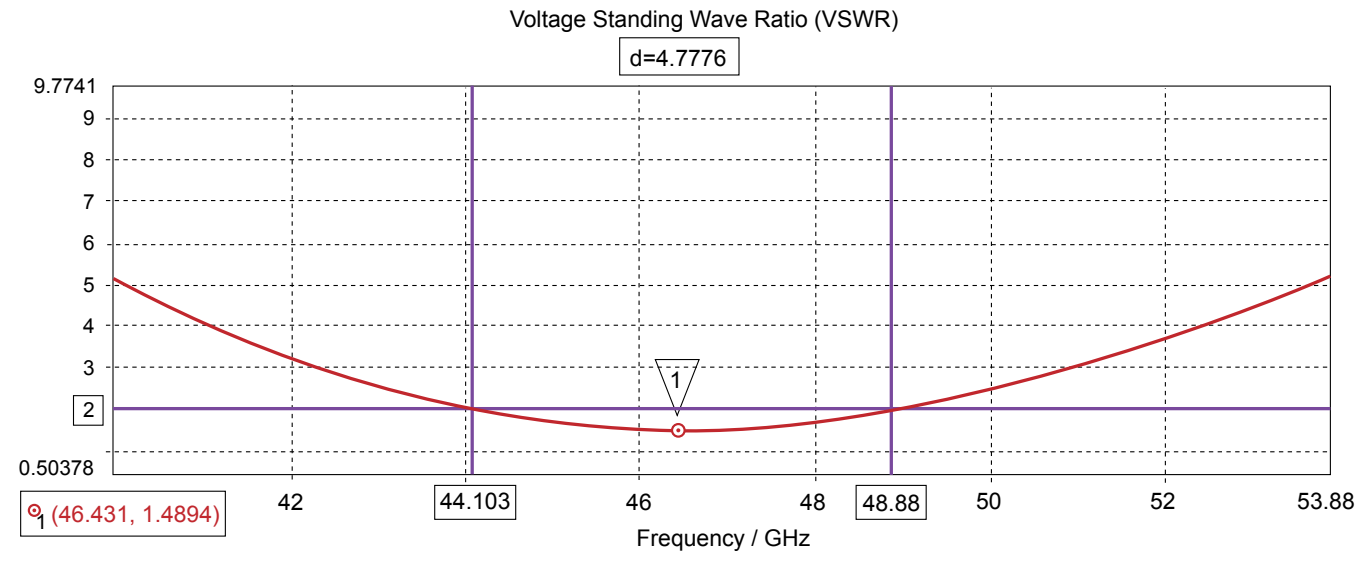

Figure 6. VSWR plot.

Source: own elaboration.

Farfield Gain Abs (Phi=90)

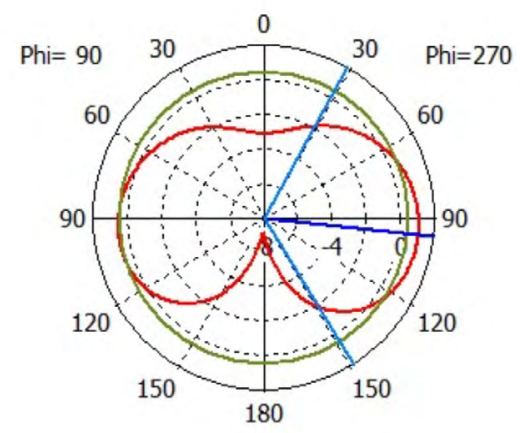

Theta / Degree vs. dB

\section{farfield $(f=46.36)[1]$}

Frequency $=46.36 \mathrm{GHz}$

Main lobe magnitude $=1.04 \mathrm{~dB}$

Main lobe direction $=96.0 \mathrm{deg}$.

Angular width $(3 \mathrm{~dB})=119.3 \mathrm{deg}$.

Side lobe level $=-0.5 \mathrm{~dB}$

Figure 7. Polar plot of far-field gain for elevation plane.

Source: own elaboration. 


\section{Farfield Gain Abs (Theta $=90$ )}

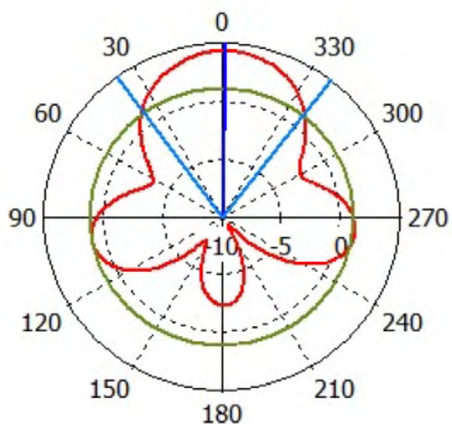

Phi / Degree vs. dB

_ farfield $(\mathrm{f}=46.36)[1]$
Frequency $=46.36 \mathrm{GHz}$
Main lobe magnitude $=\quad 4.31 \mathrm{~dB}$
Main lobe direction $=359.0 \mathrm{deg}$.
Angular width $(3 \mathrm{~dB})=74.1 \mathrm{deg}$.
Side lobe level $=-3.1 \mathrm{~dB}$

Figure 8. Polar plot of far-field gain for azimuthal plane.

Source: own elaboration.

The proposed Vivaldi antenna structure resonates at a frequency of $46.44 \mathrm{GHz}$ with a very low S1 1 value of $14.129 \mathrm{~dB}$ as in Figure 5 which ensures negligible reflection, at the resonant frequency. It is observed that the proposed antenna operates within an abnormally wide bandwidth of nearly $28 \mathrm{GHz}$ for VSWR $<2$. Also note that VSWR is very low (nearly Unity) (1.4894) at the resonant frequency as in Figure 6. For a constant, $\theta$ is varied and the main lobe magnitude variations are noted in the elevation plane in Figure 7, the magnitude of the main lobe is only $1.04 \mathrm{~dB}$ which is at an angle of $96^{\circ}$ with an Angular width ( $3 \mathrm{~dB}$ beam width) of $119.3^{\circ}$. Higher beam width can be used for frequency scanning operations but here higher gain with a lower beam width is preferred.

The $3 \mathrm{~dB}$ beam width can be technically referred to as half power beam width [HPBW] as the power at the $3 \mathrm{~dB}$ points will be half the maximum peak power. Apart from the major lobe, some minor lobes and back lobes called as the side lobes are also realized, which are minimized in this structure to ensure a minimum side lobe level of $-0.5 \mathrm{~dB}$ as in Figure 7. similarly, in Figure 8 for a constant $\theta, \varnothing$ is varied and the main lobe magnitude variations are noted in the azimuthal plane, the magnitude of the main lobe is around $4.31 \mathrm{~dB}$ which is at an angle of $359^{\circ}$ with an Angular Width of $74.1^{\circ}$.

\subsection{MICROSTRIP PATCH ANTENNA WITH INSET FEED}




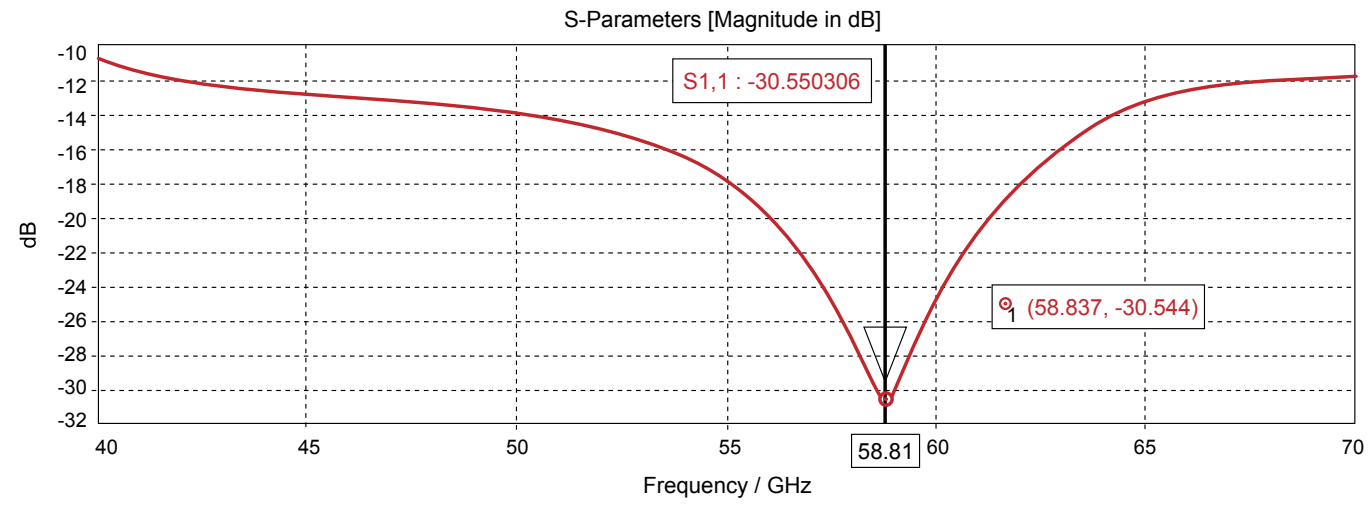

Figure 9. S11 plot.

Source: own elaboration.

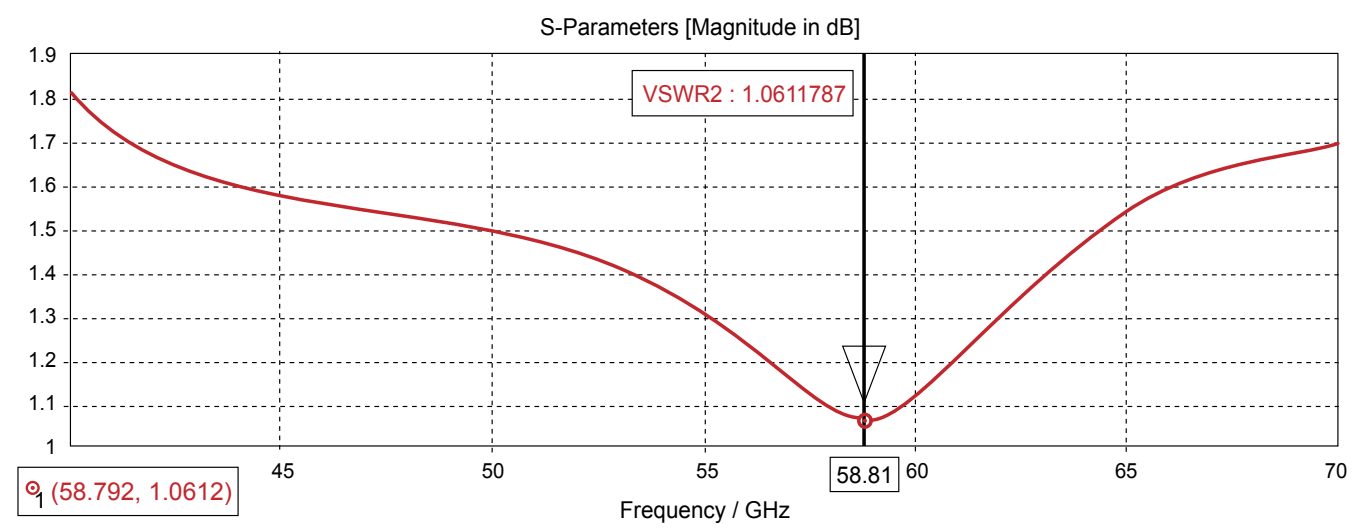

Figure 10. VSWR.

Source: own elaboration.

Farfield Gain Abs (Phi=90)

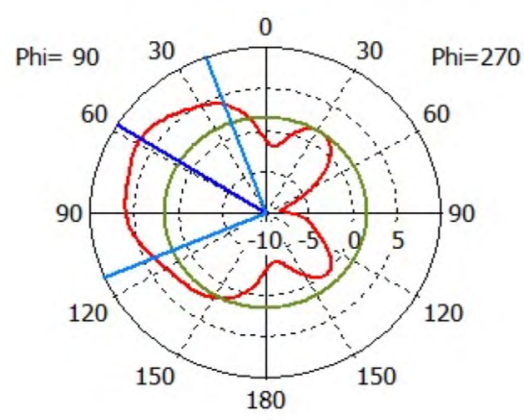

Theta / Degree vs. dB
— farfield $(f=58.81)[1]$

Frequency $=58.81 \mathrm{GHz}$

Main lobe magnitude $=6.84 \mathrm{~dB}$

Main lobe direction $=58.0 \mathrm{deg}$.

Angular width $(3 \mathrm{~dB})=93.0 \mathrm{deg}$.

Side lobe level $=-5.3 \mathrm{~dB}$

Figure 11. Polar plot of far-field gain in elevation plane.

Source: own elaboration. 
Farfield Gain Abs (Theta $=90)$

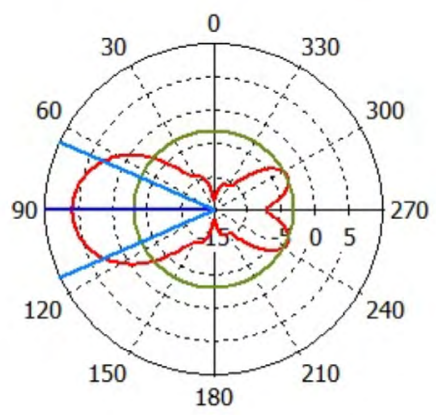

Phi / Degree vs. dB
— farfield $(f=58.81)[1]$

Frequency $=58.81 \mathrm{GHz}$

Main lobe magnitude $=5.86 \mathrm{~dB}$

Main lobe direction $=90.0 \mathrm{deg}$.

Angular width $(3 \mathrm{~dB})=48.2 \mathrm{deg}$.

Side lobe level $=-9.0 \mathrm{~dB}$

Figure 12. Polar plot of far-field gain in azimuthal plane.

Source: own elaboration.

The proposed microstrip patch antenna structure resonates at a frequency of $58.837 \mathrm{GHz}$ with a very low S11 value of $-30.544 \mathrm{~dB}$ as in Figure 9, which ensures negligible reflection, at the resonant frequency. It is observed that the proposed antenna operates within an abnormally wide bandwidth of nearly $30 \mathrm{GHz}$ for VSWR $<2$. Also note that VSWR is very low (nearly Unity) (1.06) at the resonant frequency as in Figure 10. For a constant $\varnothing, \theta$ is varied and the main lobe magnitude variations are noted in the elevation plane in Figure 11 , the magnitude of the main lobe is only $6.84 \mathrm{~dB}$, which is at an angle of $58^{\circ}$ with an Angular width ( $3 \mathrm{~dB}$ beam width) of $93^{\circ}$ and a minimum side lobe level of $5.3 \mathrm{~dB}$. similarly, in Figure 12 for a constant $\theta, \varnothing$ is varied and the main lobe magnitude variations are noted in the azimuthal plane, the magnitude of the main lobe is around $5.86 \mathrm{~dB}$ which is at an angle of $90^{\circ}$ with an angular width of $48.2^{\circ}$.

\section{CONCLUSIONS}

The proposed Antenna Miniaturization technique can be more affordable and simpler than massive MIMO to achieve $5 \mathrm{G}$ performance and to meet the ever-growing demand for thinner mobile phones. Simulation, analysis and optimization of the proposed antennas were performed by using CST simulation software. These antennas can be deployed in radio navigation satellite and earth exploration satellite applications. Usage of high frequencies causes the transmitted signal to resist interferences in its transmission path, which makes the signal reach longer distances with reduced energy consumption. 


\section{REFERENCES}

Balanis, C. A. (2005). Antenna theory: analysis and design. Wiley-Blackwell.

Bhartia, P., Tomar, R. S., \& Rao, K. V. S. (1991). Millimeter-wave microstrip and printed circuit antennas. Artech House.

Ghong, L. P., Ng, P. T., \& Fu, J. S. (2003). Secure $77 \mathrm{GHz}$ Vivaldi antenna for millimeter wave communication. In IEEE 37th Annual 2003 International Carnahan Conference On Security Technology, 100-103. https://ieeexplore.ieee.org/document/1297543

Kraus, J. D. (1951). Antennas for all applications. In Science (Vol. 113). https://doi. org/10.1126/science.113.2927.131

Li, X., \& Li, G. (2010). Design of high gain multiple U-slot microstrip patch antenna for wireless system. In 2010 International Conference on Computational Problem-Solving, ICCP, (1), 256-259. https://ieeexplore.ieee.org/document/5696064

Picher, G., Anguera, J., Bujalance, A., Andújar, A., \& Puente, G. (2013). Analysis of a multiband monopole handset antenna combined with a slotted ground plane. Microwave and Optical Technology Letters, 55(11), 173-180. https://www.recercat.cat/ handle/2072/225163

Pozar, D. M., \& Schaubert, D. H. (1995). Microstrip antennas: The analysis and design of microstrip antennas and arrays. https://ieeexplore.ieee.org/book/5263382

Priyadarshi, R., Singh, M. P., Tripathi, H., \& Sharma, P. (2017). Design and performance analysis of vivaldi antenna at very high frequency. In 2017 4th International Conference on Image Information Processing, ICIIP, 450-453. https://doi. org/10.1109/ICIIP.2017.8313758

Rappaport, T. S., Murdock, J. N., \& Gutierrez, F. (2011). State of the art in 60-GHz integrated circuits and systems for wireless communications. Proceedings of the IEEE, 99(8), 1390-1436. https://doi.org/10.1109/JPROC.2011.2143650

Verma, S., Mahajan, L., Kumar, R., Saini, H. S., \& Kumar, N. (2016). A small microstrip patch antenna for future $5 \mathrm{G}$ applications. In 2016 th International Conference 
on Reliability, Infocom Technologies and Optimization, ICRITO: Trends and Future Directions, 460-463. https://doi.org/10.1109/ICRITO.2016.7784999 